\title{
Academic general practice: reflections on a 60-year journey
}

The 60th anniversary of the founding of the NHS took place in 2008. The first academic department of general practice in the modern era also dated from the 'due date' for the start of the NHS on 1 July when the University of Edinburgh established its 'academic general practice' in the former Mackenzie House Public Dispensary within its Department of Social Medicine. By 2000, there were 27 departments of general practice in the traditional medical schools of the UK (the department in Trinity College Dublin has traditionally been included in this grouping). The history of their evolution and development has been interesting but not always straightforward; often a source of frustration but eventually one of achievement and satisfaction. This essay tries to tease out some of the issues that have had to be faced up to on the journey.

\section{TIMELINES}

Three parallel sets of timelines provide some context.

\section{Within the UK}

The NHS began in 1948 and the highly critical Collings' Report in $1950^{1}$ led to the foundation in 1952 of the College of General Practitioners, one of whose first aims was to see established a department of general practice in every UK medical school. The Edinburgh department became independent in 1956 and its chair followed in 1963. Between 1970 and 1972 three other chairs were established in Scotland. Manchester (1972) led the way in England, but it took until 1995 for all schools to follow. From 1971 onwards regional (postgraduate) advisors were appointed in all UK regions, mostly with connections to medical schools through postgraduate deans. In Exeter, a postgraduate chair was established in 1986.

The emerging cohort of undergraduate departments held its first scientific meeting in 1972 in Cardiff, and the AUTGP (Association of University Teachers of
General Practice) was established as its scientific society in 1974 (later becoming the Association of University Departments of General Practice [AUDGP]) and - in 2000 - SAPC (the Society of Academic Primary Care). Although these organisations were constituted as scientific organisations, their members (originally, but not now, mainly doctors) also saw their existence as necessary to take forward structural agendas that were not being sufficiently addressed elsewhere. Of greatest importance was the absence of adequate and equitable core funding from either the NHS or the university funding systems, in marked contrast to the very considerable NHS budgets available to support postgraduate education and the regional advisor infrastructure. The negotiations to address this problem took from 1981 until 1992, and their successful conclusion with the establishment of GP SIFT in England (Service Increment For Teaching) and the parallel GP ACT in Scotland (Addition for Clinical Teaching) marked a watershed in the capacity of undergraduate departments to flourish and achieve their potential. During these protracted negotiations, the General Medical Services Committee (GMSC) of the British Medical Association (BMA) was particularly helpful in opening negotiating channels to the then Department of Health and Social Security.

\section{Abroad}

It is easy to view the evolution of academic general practice from a narrow UK perspective. However, the world's second chair was established in 1966 in Utrecht, and its holder (Jan van Es) referred to the mushrooming of chairs around the north Atlantic countries as a process of 'simultaneity'. ${ }^{2}$ Europe developed its own academic institution SIMG (Societas Internationalis Medicinae Generalis) in 1962, and Wonca (World Organization of National Colleges, Academies and Academic Associations of General Practitioners/Family Physicians) was inaugurated in 1972. In 1974, the Leeuwenhorst Group (defining the discipline of general practice) and the EGPRW (European General Practice Research Workshop), SIMG and EGPRW were all amalgamated within Wonca Europe in 1996.

\section{Organisations and structures}

Several structural events have greatly influenced the evolution of general practice in the UK. The 1966 'Charter' opened the way for the construction of modern general practice by encouraging the development of group practices and the employment of interdisciplinary and clerical staffing. In 1990 the twin initiatives of general practice fund-holding and the institution (imposition) of a then 'new contract' emerged. This was replaced in 2004 by the present contract. Patients are now registered with practices rather than a personal doctor; doctors have largely opted out of 24-hour responsibility for patient care; and the QOF (Quality and Outcomes Framework) payment structure has shifted the emphasis at consultations away from giving priority to the agendas of patients towards meeting targets which, inter alia, relate to the generation of practice income.

In 1973, the MRC (Medical Research Council) established its General Practice Research Network (GPRN) to help recruit patients for national studies it was supporting. The JCPTGP (Joint Committee on Postgraduate Medical Education) was created in 1975 - the AUDGP having one representative on it and vocational training for general practice became mandatory in 1982. The Department of Health established the National Primary Care Research and Development Centre (NPCRDC) in Manchester in 1996.

These overlapping sets of dates show how many and how complex have been the influences surrounding academic general practice and its evolution over 60 years. 


\section{A UNIVERSITY DISCIPLINE AND ITS PURPOSE}

There have been several attempts to define the criteria of a University clinical discipline. Two are closely similar. McWhinney in $1966^{3}$ and Richardson in $1975^{4}$ both included the presence of a unique body of knowledge, having specific clinical skills, and the ability to support original research in their sets of four key criteria. McWhinney's fourth criterion was the ability to manage its own postgraduate training; Richardson's was the possession of a philosophy. From a different perspective, Pereira Gray has argued that a subject becomes an academic discipline when it has its own literature. $^{5}$

Those who work in clinical disciplines also provide service care, and many of the early departments were constructed round busy inner city practices with heavy workloads. In 1986, the Mackenzie Report described the juxtaposition of medical schools and service general practice in this way:

\section{'Universities are hierarchical organisations whereas general practice is strongly egalitarian; Universities emphasise research and theory, whereas general practice has evolved from experience and instinct ...' ${ }^{6}$}

One important role of 'academic general practice' (defined for the present purpose as the undergraduate departments in the traditional medical schools) has been to build bridges between the two very different cultures of medical schools and service general practice. Four areas of work have been involved: teaching about medicine in the setting of the community; carrying out research to establish the nature of general practice and to improve delivery of clinical care; contributing to the organisation and administration of universities and the NHS; and contributing to the wider philosophy of medical practice and its role in society. Have the departments of general practice succeeded in these roles?

Within medical schools, the answer must be 'yes'. Around $15 \%$ of the undergraduate curriculum is now taught under the supervision of departments of general practice. General practice research figured prominently in the Research Assessment Exercises (RAEs) of 1992, 1996 and 2001, although, significantly, its individuality was compromised in the 2007 RAE when the research from the majority of general practice researchers was declared within other research categories than general practice. The undergraduate departments have contributed strongly to the literature of the discipline and thus to the creation of the current evidence base of clinical practice. And their staff have been prominent in the wider life of medical school administration, and there and elsewhere have contributed significantly to the evolving understanding of the relationships between medicine and society.

\section{THREE TENSIONS}

The histories of the developing departments tell of individuals with vision, drive, and perseverance who overcame many obstacles on the way to achieving their aims. They say relatively little about those with power or influence who were either positively obstructive or simply failed to show the leadership that could have made progress so much easier.

Three more general issues added to the difficulties faced by the emerging discipline.

\section{'Real doctors' or 'real academics'}

Certainly in the early years, but probably less so now, there has been a tension over whether academic GPs were proper doctors or proper academics. Many early academic staff would have claimed public health as their basic clinical discipline, and service GPs were unconvinced of their ability to speak the language of 'ordinary' doctors. Even those coming to universities from a clearly general practice background lost credibility when their responsibilities for patients became diminished, particularly through their inability to provide either continuing or comprehensive care. At the same time, the appointment of doctors to senior university posts without higher research degrees or significant records of contribution to peer-reviewed literature created scepticism within universities, compounded by the award to them of top clinical salaries against the prevailing lower incomes of academic staff in other faculties and of non-clinical staff in medical faculties.

Most of the first departments were built round service general practices staffed mainly or exclusively by universityemployed staff (who were paid on the non-consultant clinical scales). The hope (of universities) was that income generated from patient care would contribute significantly to the costs of these departments, but service income never proved able to support an adequate academic infrastructure. In addition, although list sizes were normally smaller than standard, the very nature of the direct availability of doctors in general practice to their patients resulted in clinical work taking priority over academic work, often confirming the view of those in other academic disciplines that academic general practice lacked academic credibility. Conversely, a number of departments (now virtually all) were created on the assumption that academic staff would develop separate clinical connections with existing local practices. This has created a different set of contractual difficulties (there is still no equivalent of an honorary consultant in a hospital discipline) for academic GPs. The clinical credibility of those holding such posts has depended on their personal track records as family doctors, 
but their academic output has tended to be more substantial than that of many of those in the early 'practice-based' departments.

\section{Undergraduate and postgraduate medicine}

At the local level, undergraduate and postgraduate general practice has normally (but not always) integrated well. Many early vocational training programmes were created from within undergraduate departments, and dayrelease programmes have gained much from the contributions of those actively involved in research in the undergraduate setting. In many places, research training posts were created under the auspices of postgraduate medicine and funding, but housed and supervised within the undergraduate departments. Undergraduate staff have also contributed significantly to the continuing education of GPs.

At the national and political level, the need for undergraduate and postgraduate departments to establish their own spheres of influence has sometimes created tensions. The establishment of the AUTGP was a response to the emergence of needs and priorities within the university system which were different from those of the RCGP. The relative distancing of regional advisors from undergraduate departments reflected the reality that supervision of vocational training had become a major role for the RCGP and for many of its leading figures, replacing the College's role in its early years as a driver of undergraduate education attachments and of general practice research. Nonetheless, at a personnel level, many leading players have had multiple roles, exemplified by the writing of The Future General Practitioner in $1972,^{7}$ published by the BMA, but the result of an RCGP working party, most of whose members were or became leading 'academic' thinkers.

One consequence of the different paths followed by the College and the university departments has been their very different involvements in international academic affairs. While the College took a significant role in the development of
SIMG, the Leeuwenhorst Group, EGPRW and Wonca, the undergraduate departments played almost no role in any of them. Probably this reflected the need of those within universities to devote maximum effort to local pressures, but it also gave space to those outside the university system to pioneer different agendas. At the same time, individual academics and departments have contributed significantly to the development of general practice both as a clinical and as an academic discipline worldwide.

\section{General practice or public health}

The third tension has been that between the disciplines of general practice and public health. At one level, this has been an issue within universities. Although nearly all emerging departments of general practice required the patronage of departments of public health to grow, achieving independence from them thereafter was an inevitable evolutionary step. The tension between the emphasis of general practice on the needs of individual patients and that of public health on population medicine and the organisation of health services generally has been the public face of this dilemma, but the reluctance of departments of general practice to be seen merely as facilities for data collection for the epidemiological studies of others has been equally important. Now the emphasis is changing again, with universities wanting to merge small departments into larger ones, and the present risk is that this will result in general practice research moving more into disease-centred rather than patientcentred enquiry. This trend has already become evident in the 2007 RAE where the separate identity of general practice research has been greatly diminished by its repositioning within other units of assessment in many universities, materially threatening the longer term future of general practice as an independent clinical discipline within medical schools.

Within the NHS, current initiatives to restructure general practice services reflect a shifting NHS emphasis towards public health agendas which may be quite different from the agendas of consulting patients. ${ }^{8}$ In parallel, the increasingly frequent renaming of general practice as primary care warns of the possibility that general practice may in future not be a GP-led service.

\section{A SECOND GENERATION}

Academic general practice looks very different in 2010 as compared to in the 1970s. The renaming in 2000 of the discipline's scientific body from the AUDGP to the SAPC captured appropriately both the timing and the nature of what has almost amounted to a 'paradigm shift' in the discipline's profile. The discipline is now significantly more professional. Staff are much better trained in research methods, and the wide network of well briefed and supervised teaching general practices provides an enviable base for clinical teaching. The disciplinary spread is much wider than it was, although few of today's medical staff have had the depth of experience of full-time service practice that most of their predecessors had.

Academic general practice has had a challenging 60-year lifespan. Its impact on the culture of medical schools has been visibly successful; its impact on the culture of service general practice has been harder to judge. In both spheres progress has been complicated (often unnecessarily) by issues of clinical and academic credibility, ownership of professional territory, and disciplinary identity. Many groups with differing agendas have been and still are competing for influence.

If academic general practice, whether by that name or as academic primary care (or even perhaps under some new name that better reflects other endangered elements of its original parent clinical discipline such as continuity and comprehensiveness of care), is to continue to make a distinctive contribution in the future, it must be doubly sure of its contemporary identity and equally clear about its future aims.

\section{John GR Howie}

(This essay is based on a presentation at the 60th anniversary celebrations of the Edinburgh 
University Department of General Practice in Edinburgh during November 2008).

\section{REFERENCES}

1. Collings JS. General Practice in England today: A Reconnaissance. Lancet 1950; i: 55-85.

2. Loudon I, Horder J, Webster C. Developments in other countries. In: General Practice under the National Health Service 1948-1997. London: OUP, 1998: 256.

3. McWhinney IR. General practice as an academic discipline. Lancet 1966; i: 419-23.

4. Richardson IM. The value of a university department of general practice. $B M J 1975$; iv: 740-742.

5. Pereira Gray DJ. Forty years on: the story of the first forty years of the Royal College of General Practitioners. London: RCGP, 1992.

6. Howie JGR, Hannay DR, Stevenson JSK. The Mackenzie Report. General practice in the medical schools of the United Kingdom - 1986. Edinburgh: University of Edinburgh, 1986

7. Royal College of General Practitioners. The future general practitioner: Learning and Teaching. London: RCGP, 1972.

8. Howie JGR, Metcalfe DHH, Walker JH. The state of general practice - not all for the better. BMJ 2008: 336:1310.

DOI: 10.3399/bjgp10X515205

\section{The Research Paper of the Year Award 2009}

Earlier diagnosis of cancer is a compelling objective for GPs and this year's RCGP Paper of the Year makes a significant contribution in the case of ovarian cancer. ${ }^{1}$ The Bristol team led by Willie Hamilton undertook a case-control study using GP records in 39 Devon practices as part of the prevention and early diagnosis programme of the School for Primary Care Research. ${ }^{2}$ Their project identified seven symptoms which could help clinicians to diagnose ovarian cancer at an earlier stage than we achieve at present: abdominal distension; postmenopausal bleeding; loss of appetite; increased urinary frequency abdominal pain; rectal bleeding; and abdominal bloating. The study concluded:

\section{'Women with ovarian cancer usually have symptoms and report them to primary care, sometimes months before diagnosis. This study provides an evidence base for selection of patients for investigation, both for clinicians and for developers of guidelines'.}

As Frede Olesen pointed out in his contribution to the UK Academy of Medical Science report last year, that evidence base is needed worldwide and British general practice could and should be contributing more to providing it. ${ }^{3}$

The UK has developed an excellent system of patient care with near universal electronic records and research networks which enable practices and academics to address important issues. ${ }^{4}$ As the RCGP and academic groups work more closely together we are also now developing the ability for primary care clinicians to influence the agenda being pursued by research teams. Readers of the BJGP and College members attending the RCGP Annual Primary Care Conference will notice that the studies being undertaken are of increasing clinical relevance. They should also take the opportunity to influence the research agenda provided by the improved communication channels for example through the Clinical Innovation and Research Centre (CIRC). ${ }^{5}$

The Research Paper of the Year Award is one strand of the work undertaken by CIRC. The award has been presented by the RCGP each year since 1996 to raise awareness of high quality studies taking place within general practice and to encourage more GPs to become actively involved in research. The findings from the 2009 award winning paper were widely reported in the mass media and have been rapidly picked up by several ovarian cancer awareness charities, including Ovarian Cancer Action, which highlighted the early indicators in its Remember the Symptoms campaign in March 2010. ${ }^{6}$ We also hope that the winning paper's messages are being integrated into undergraduate and postgraduate curricula to influence the care we deliver.

\section{Frank Sullivan}

\section{REFERENCES}

1. Hamilton W, Peters TJ, Bankhead C, Sharp D. Risk of ovarian cancer in women with symptoms in primary care: population based case-control study. BMJ 2009; 339: b2998.

2. NHS National Institute for health Research. School for Primary Care Research. Programme 1. Prevention and early diagnosis.

http://www.nspcr.ac.uk/ThemeDetails.cfm?ID=1 (accessed 12 Jul 2010).

3. The Academy of Medical Sciences. Research in general practice: bringing innovation into patient

http://www.acmedsci.ac.uk/index.php?pid=44\&evid= 102 (accessed 12 Jul 2010).

4. Sullivan F, Butler C, Cupples M, Kinmonth AL. Primary care research networks in the United Kingdom. BMJ 2007; 334:1093-4.

5. RCGP. Clinical Innovation and Research Centre (CIRC).

http://www.rcgp.org.uk/clinical_and_research/circ.as px (accessed 12 Jul 2010).

6. Ovarian Cancer Action. What every woman should know about ovarian cancer.

http://www.ovarian.org.uk/ovariancancer/whatyoush ouldknow.asp (accessed 12 Jul 2010).

DOI: 10.3399/bjgp10X515214 